\title{
Two Types of Sunburn in Apple Caused by High Fruit Surface (Peel) Temperature
}

Larry E. Schrader, Professor of Plant Physiology, J ianguang
Zhang, Visiting Professor of Pomology, and William K. Duplaga, Agricultural Research Technologist, Washington State University Tree Fruit Research \& Extension Center, Wenatchee, WA, USA 98801

Corresponding author: Larry E. Schrader. schrader@wsu.edu

Schrader, L. E., Zhang, J., and Duplaga, W. K. 2001. Two types of sunburn in apple caused by high fruit surface (peel) temperature. Online. Plant Health Progress doi: 10.1094/PHP-2001-1004-01-RS.

\begin{abstract}
Sunburn of apple costs growers millions of dollars in economic losses annually. We have identified two types of sunburn in apple and their causes. The first (sunburn necrosis) is caused by thermal death of epidermal and subepidermal cells (peel), and causes a necrotic spot on the sun-exposed side of the fruit. Thermal death occurs at $126 \pm 2^{\circ} \mathrm{F}\left(52 \pm 1^{\circ} \mathrm{C}\right)$. Electrolyte leakage increases significantly with necrosis, indicating that membrane integrity is lost during thermal death. The second type (sunburn browning) is sublethal and results in a yellow, bronze, or brown spot on the sun-exposed side of the fruit. Sunburn browning occurs at a fruit surface temperature of 115 to $120^{\circ} \mathrm{F}\left(46\right.$ to $49^{\circ} \mathrm{C}$ ) and has little effect on membrane integrity, but sunlight is required for sunburn browning.
\end{abstract}

Sunburn causes important economic losses in a large number of fruits and vegetables (1). Sunburn and sunscald have been used interchangeably in the literature, and this has caused confusion. The American Phytopathological Society (5) defined sunburn as damage to fruit by exposure to solar radiation, and defined sunscald as injury to the bark and underlying tissues caused by freezing. We therefore use the term sunburn to describe this fruit disorder.

In Washington State and several other regions of the world, sunburn causes serious economic losses in apples [(Malus sylvestris (L.) Mill var. domestica (Borkh.) Mansf.] $(2,8,10)$. In 1926, Brooks and Fisher (3) reported that fruit surface temperatures on the sun-exposed side of fully exposed fruit were up to $25^{\circ} \mathrm{F}$ above air temperatures and concluded that injury to apples resulted from heat, and not from other radiation effects. In contrast, Rabinowitch et al. (7) reported that in addition to heat, visible light was necessary for development of typical sunburn symptoms in tomatoes. They concluded that sunburn is caused by the concurrent action of two external factors, heat and light. Rabinowitch et al. (6) later reported that fruit skin temperature thresholds of 38 to $40^{\circ} \mathrm{C}$ (100 to $\left.104^{\circ} \mathrm{F}\right)$ and 40.5 to $42.5^{\circ} \mathrm{C}\left(105\right.$ to $\left.108^{\circ} \mathrm{F}\right)$ were found to be essential for development of sunburn injury in cucumbers and peppers, respectively. Light in the visible spectrum was found to be essential, as no bleaching occurred in the dark. They suggested that sunburn occurs when photosynthesis is disturbed by excessive heat, so that light energy is redirected into damaging photodynamic processes.

To better understand sunburn of apple, we examined the effects of sunlight and fruit skin temperature on incidence of sunburn damage. Two types of sunburn were distinguished in apple. We call the first type "sunburn necrosis" and the second type "sunburn browning." In this paper, we present evidence that fruit skin (peel) temperature is critical to development of both types of sunburn in apples, and that solar irradiation is required for sunburn browning. 


\section{Visual Depiction of Sunburn Necrosis Versus Sunburn \\ Browning}

Apples with sunburn necrosis and sunburn browning are compared in Fig. 1. Gala and J onagold apples in the early stages of necrosis are shown in Figs. 1A and $1 \mathrm{~B}$, and an advanced stage of necrosis for Fuji is shown in Figs. 1C. Sunburn browning results in different degrees of injury, but typically appears as a brown, yellow, or bronze spot on the sun-exposed side of the fruit (See Figs. 1D to F). The degradation of chlorophyll is accelerated in apple peel as sunburn browning occurs (unpublished data of Kochhar and Schrader). Although sunburn browning sometimes seems to disappear as fruit matures, the disorder is not reversible. Instead, anthocyanins and other pigments sometimes mask these symptoms as fruit color up with maturity (unpublished data).

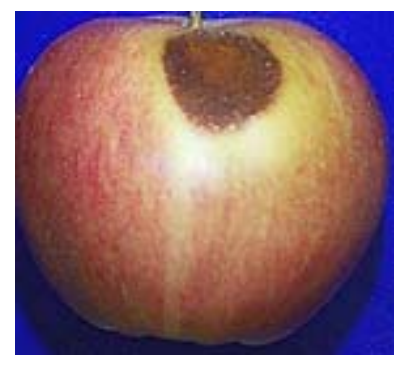

A

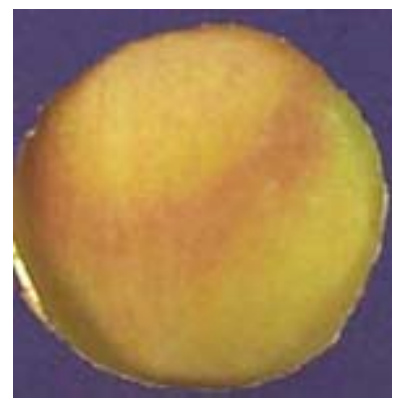

D

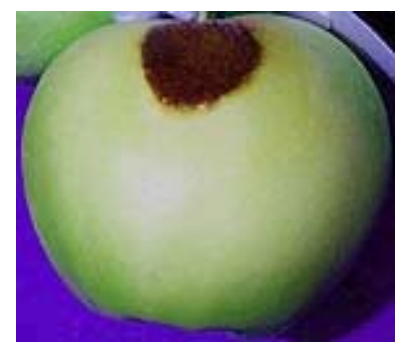

B

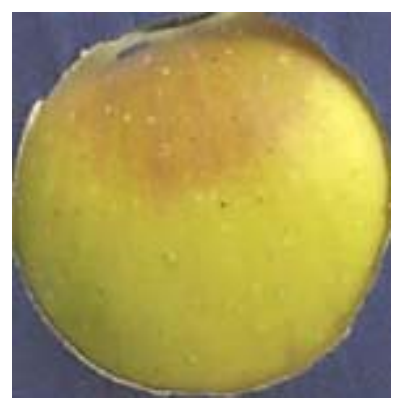

$\mathbf{E}$

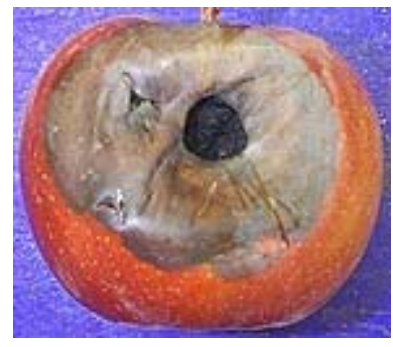

C

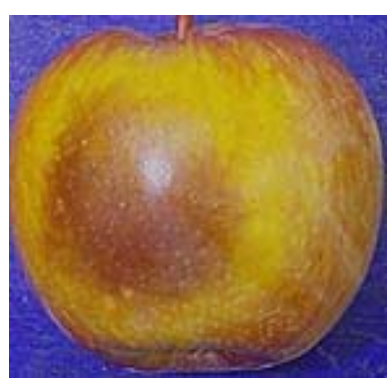

$\mathbf{F}$

Fig. 1. Sunburn necrosis ( $A$ to $C$ ) and sunburn browning ( $D$ to $F$ ). $A$ and $D$ are Gala; $B$ and $\mathrm{E}$ are Jonagold; $\mathrm{C}$ and $\mathrm{F}$ are Fuji.

\section{I nduction of "Sunburn Necrosis" in Apples}

Experiment 1. Three techniques were used to heat apples in situ to induce sunburn necrosis. A reading lens, an electrical heating device, and a "black patch method" were used. With the reading lens and heating device, the fruit was exposed directly to solar irradiance whereas with the black patch method, the heated fruit surface was dark during the 10-minute heating period. All three methods provided the same result. Therefore light is not required to induce necrosis. With the black patch method, a small square $(2.5 \times 2.5 \mathrm{~cm})$ of aluminum foil was painted black, the reverse side was coated with a sticky material, and the patch was placed on the sun-exposed side of the fruit (Fig. 2). A fine copper-constantan thermocouple (0.254-mm diameter wire) was attached to a psychrometric microvoltmeter (Keithley Instruments, Inc., Cleveland, $\mathrm{OH}$ ) and placed under the black patch with good contact to the fruit peel. The peel under the black patch was heated quickly in full sunlight, and the fruit was rotated as needed to keep the fruit at a constant temperature for the treatment time. In most experiments, the fruit was heated for only $10 \mathrm{~min}$, and then the black patch was removed. 


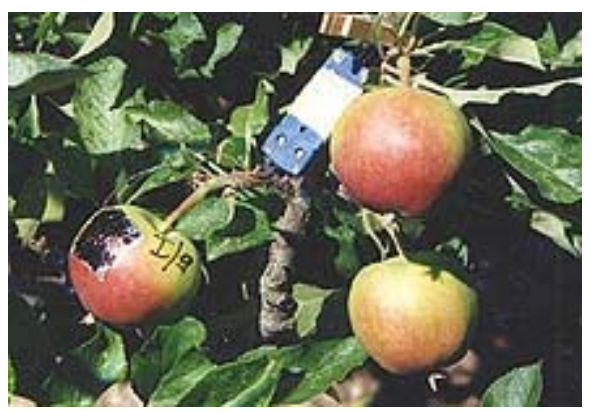

Fig. 2. Black patch method used to intercept solar irradiance and to heat pee of attached fruit in the field. A fine thermocouple attached to a psychrometric microvoltmeter was inserted under the black patch to measure peel temperature.

The black patch technique was used with apples of several cultivars at different stages of development. When the fruit surface temperature reached 126 $\pm 2^{\circ} \mathrm{F}$ for $10 \mathrm{~min}$, sunburn necrosis developed in a few days. A typical result is shown in Fig. 3 in which 'Gala' apples were treated at either $122^{\circ} \mathrm{F}$ (apple on the right) or $126^{\circ} \mathrm{F}$ (apple on the left) for $10 \mathrm{~min}$, and photographed at intervals thereafter. Photobleaching appeared the next day in the apple heated to $126^{\circ} \mathrm{F}$ (Fig. 3A). Four days later, some necrosis appeared (Fig. 3B), and after 7 days , more serious necrosis was evident (Fig. 3C) in the apple heated to $126^{\circ} \mathrm{F}$. No damage was apparent in the apple heated to $122^{\circ} \mathrm{F}$. In other experiments (data not shown), apples were heated 20 or $30 \mathrm{~min}$, but the symptoms were similar to those observed at $10 \mathrm{~min}$. The results with several other cultivars also were similar. These findings indicate that necrosis of the apple peel occurs after 10 min at $126 \pm 2^{\circ} \mathrm{F}$. Light was not required during the 10 -min induction period.

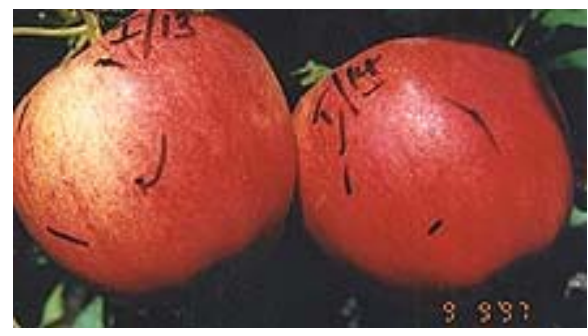

A

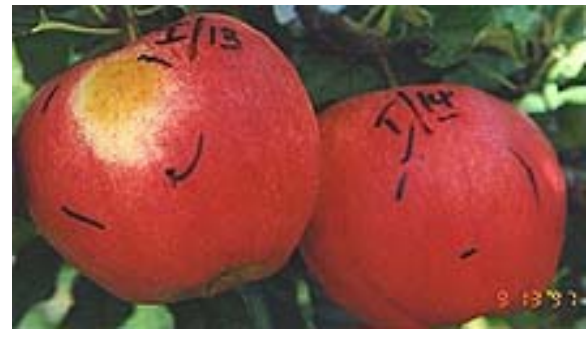

B

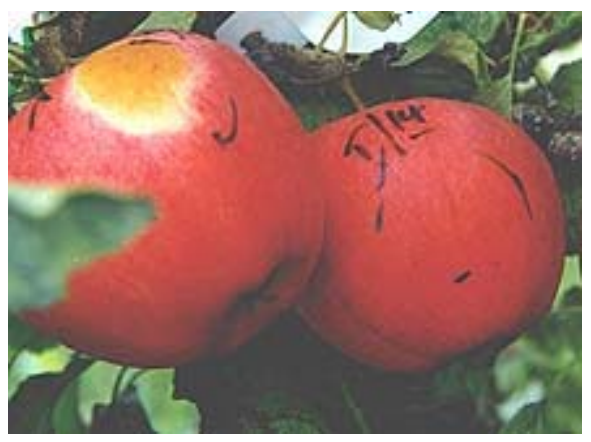

C

Fig. 3. The use of black patch method to induce sunburn in Gala apples. Apple on the left in each photo was heated to $126^{\circ} \mathrm{F}$ and apple on the right was heated to $122^{\circ}$ $\mathrm{F}$ for $10 \mathrm{~min}$. Photos A, B, and C were taken 1,4 , and 7 days after heating. 
Experiment 2. A calibrated infrared thermometer and data logger (Extech Instruments, Inc., Waltham, MA) were used to measure fruit surface temperatures of 60 fully exposed Gala apples August 4, 1997, between 1:00 and 2:00 p.m. Air temperature at the time of the measurements was 100 to $102^{\circ} \mathrm{F}$, but air temperature continued to increase to $106^{\circ} \mathrm{F}$ by 4:00 p.m. Fifteen fruit with a peel temperature exceeding $122^{\circ} \mathrm{F}$ were tagged and observed on subsequent days. Fourteen of the tagged apples developed necrosis within a few days (data not shown). Subsequent experiments on fully exposed apples with thermocouples attached on the sun side of fruit indicated that peel temperature does not reach its maximum until between 3:15 and 4:45 p.m. on a clear day. Because air temperature on August 4 increased 3 to $5^{\circ} \mathrm{F}$ after the infrared temperature measurements of fruit were made, it is highly likely that the tagged fruit reached a surface temperature of at least $126^{\circ} \mathrm{F}$. These results under natural conditions corroborate what we observed in the black patch experiments, i.e., that sunburn necrosis was induced by applying extra heat to increase fruit surface temperature to about $126^{\circ} \mathrm{F}$ for only $10 \mathrm{~min}$.

\section{I nduction of "Sunburn Browning" in Apples}

Experiment 3. Supplemental heat was applied to well-exposed fruit under controlled conditions. Fruit attached to the tree were enclosed in a plexiglass chamber (32 cm long $\times 17 \mathrm{~cm}$ wide $\times 18 \mathrm{~cm}$ high) containing a $600 \mathrm{~W}$ cone heater attached to a variable autotransformer. Experiments were conducted between J uly and October on days when mean solar radiation averaged above $800 \mathrm{~W} / \mathrm{m}^{2}$ between 1:00 and 4:00 p.m. A copper-constantan thermocouple (0.254-mm diameter wire) attached to a CR-10X data logger (Campbell Scientific, Inc., Logan, UT) recorded the fruit skin temperature at the center of the heated spot at 1-min intervals. The fruit surface temperature of treated fruit was controlled at the desired temperature $\pm 1^{\circ} \mathrm{F}$. Heat was applied for $5,10,15$, 30,60 , or 120 min and fruit surface temperatures were $113,115,117,118,120$, or $122^{\circ} \mathrm{F}$. Sunlight was excluded ("no-light treatment") by placing a metal cover on top of the chamber during heat treatment. Photographs were taken before, immediately after, and for several days after heating treatments were applied to document if and when sunburn injury appeared.

Sunburn browning was induced when fruit surfaces were heated for $1 \mathrm{~h}$ to temperatures between 115 and $120^{\circ} \mathrm{F}$. The browning appeared in the area subjected to heating and sunlight. A typical response is shown in Fig. 4 for $\mathrm{Cv}$. Gala. Sunburn browning did not appear until 3 days after heating the apples for $1 \mathrm{~h}$ at $118^{\circ} \mathrm{F}$ in sunlight (Fig. 4B). When sunlight was excluded during the heating at $118^{\circ} \mathrm{F}$ for $1 \mathrm{~h}$, sunburn browning did not occur (Fig. 4D). This indicates that, in addition to a threshold temperature of the peel, sunlight is required for sunburn browning. Preliminary experiments indicated that cultivars differ in the threshold temperature at which sunburn browning is induced. Sunburn browning appears to occur at a lower temperature in cv. Cameo as compared to Gala and Fuji, and Gala sunburns at a lower temperature than Fuji. A wider range of cultivars will be studied during 2001 to confirm these findings, and to identify which wavelengths of sunlight are required for sunburn browning. 

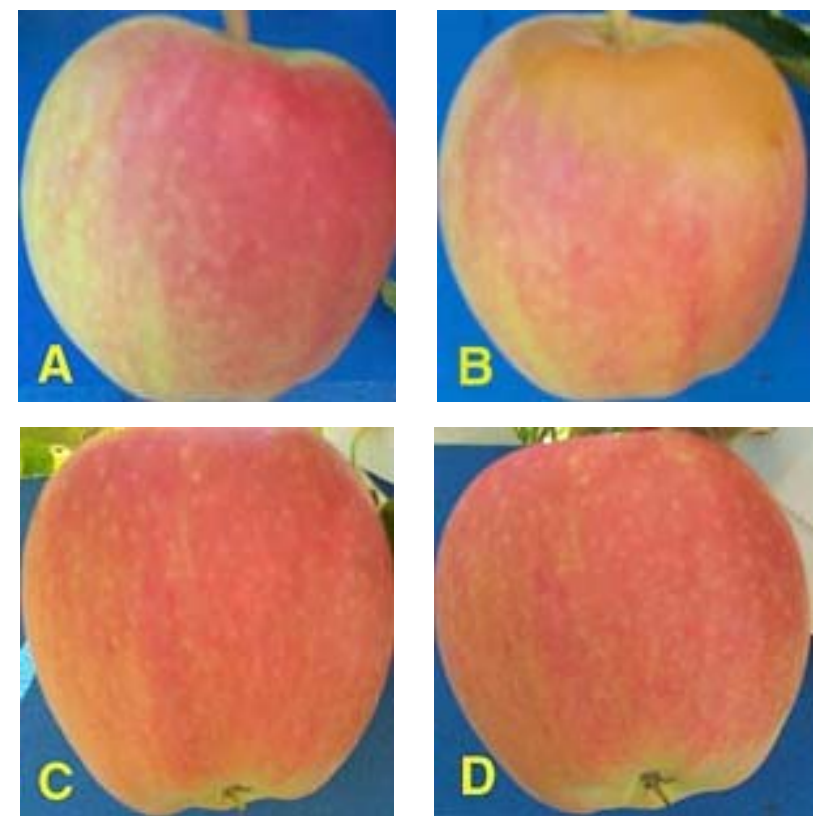

Fig. 4. The induction of sunburn browning in Gala apples. Apples were heated for $60 \mathrm{~min}$ (from 2:00 to 3:00 p.m.) at $118^{\circ} \mathrm{F}$ in sunlight or darkness. Photos $\mathrm{A}$ and $\mathrm{C}$ are were taken before treatment. Photo $B$ was taken 3 days after heating with exposure to sunlight. Photo D was taken 3 days after heating in darkness ("no-light treatment").

\section{Electrolyte Leakage from Peel Differs for Necrosis vs. Browning}

Electrolyte leakage has been used as an indicator of high-temperature injury in mature green tomatoes (4). We compared the electrolyte leakage from peel of non-sunburned (control) apples to that from peel with sunburn browning or sunburn necrosis.

Experiment 4. Fruit of three cultivars were collected and immediately transported to the laboratory. Fruit were divided into three classes: those with sunburn necrosis, those with sunburn browning, and controls (not sunburned). Three replicate samples were prepared for each class of fruit. Each sample was taken from three to five fruit representative of each class. About 20 disks/ replicate were removed with a cork borer (0.8- $\mathrm{cm}$ diameter) from various locations on the sun-exposed side of fruit from each class of fruit. Cortex cells were removed with a razor blade (the thickness of 10 disks was $16 \mathrm{~mm}$ ). Bacterial disease or invasions were not observed on any fruit. Disks ( $1.5 \mathrm{~g}$ total) were weighed on an analytical balance, placed in $40 \mathrm{ml}$ distilled water, and held at room temperature $\left(72^{\circ} \mathrm{F}\right)$ for $1 \mathrm{~h}$. Initial electrical conductivity $(\mathrm{EC})$ for each treatment was determined, as an indication of electrolyte leakage, with a Hariba Twin Cord Conductivity Meter B-173 (Horiba Instruments, Inc., Irvine, CA). Then the samples were boiled on a hot plate for $15 \mathrm{~min}$ to release remaining electrolytes from cells of the peel. Distilled water was added to restore the $40 \mathrm{ml}$ volume, and final EC was determined after solutions cooled to room temperature. Relative EC was calculated by dividing initial EC by final EC, and multiplying by 100. Percentage data were transformed using the arcsine percentage transformation (9) before statistical analysis. Duncan's new Multiple Range Test (9) was used to compare means.

In the three types of fruit, cultivar had little influence on relative EC (i.e., electrolyte leakage) (Fig. 5). The relative EC for fruit with necrosis was significantly higher $(\mathrm{P}<0.05)$ than relative EC for fruit with no sunburn or with sunburn browning (Fig. 5). This indicated that membrane integrity in necrotic fruit was destroyed and permitted electrolytes to leak freely. The relative EC for fruit with no sunburn or with sunburn browning did not differ significantly, indicating that membrane integrity was not affected by sunburn browning. These results corroborate our earlier claims that necrosis results from thermal death, but that sunburn browning is a sublethal event. 


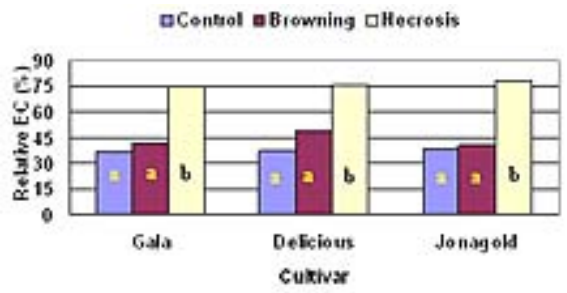

Fig. 5. Effect of sunburn browning and sunburn necrosis on electrolyte leakage (relative electrical conductivity) from peel of three apple cultivars. Bars with the same letter are not significantly different from each other at $P<0.05$ according to Duncan's Multiple Range Test.

Experiment 5. Fruit without sunburn from three cultivars were used in this test. The sampling procedures were similar to Experiment 1 except that $12 \%$ $(\mathrm{w} / \mathrm{v})$ sucrose solution was used to maintain turgor pressure of the disks. Each set of disks was incubated in a thermostatically-controlled water bath for $30 \mathrm{~min}$ at a different temperature $\left(113,117,122,127\right.$ or $\left.131^{\circ} \mathrm{F}\right)$, and then boiled for 15 min. Three EC readings were taken: initial (before heating), middle (after heating), and final (after boiling). The relative value (RV) for EC was calculated by the following equation:

$$
R V=\frac{M-I}{F-I} \times 100
$$

where $\mathrm{I}=$ initial value, $\mathrm{M}=$ middle value, and $\mathrm{F}=$ final value. Data were analyzed statistically, as described for Experiment 4.

As shown in Fig. 6, RV (i.e., electrolyte leakage) was similar for Delicious and Gala after heating at $113^{\circ} \mathrm{F}$ but both cultivars were significantly lower $(\mathrm{P}<0.05)$ than J onagold. At 117 and $122^{\circ} \mathrm{F}$, only Delicious was significantly different $(\mathrm{P}<$ $0.05)$ from Gala and J onagold. At $127^{\circ} \mathrm{F}$, all three cultivars were different $(\mathrm{P}<$ $0.05)$ from each other, and J onagold was different $(\mathrm{P}<0.01)$ from the other two. At $131^{\circ} \mathrm{F}$, electrolyte leakage was similar and complete in all three cultivars. We conclude from this experiment that electrolyte leakage differs among these three cultivars at temperatures up to $127^{\circ} \mathrm{F}$. Even though cultivar differences in RV are observed, sunburn necrosis occurs at the same temperature (i.e., $126 \pm 2^{\circ} \mathrm{F}$ ) in all cultivars studied. At this time, we can only suggest that factors other than membrane integrity also may contribute to development of necrosis.

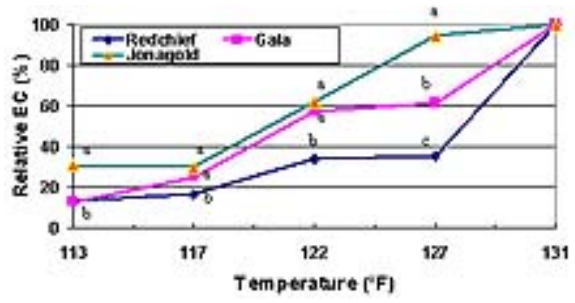

Fig. 6. Electrolyte leakage (relative electrical conductivity) of apple peel from three cultivars as influenced by incubation temperature for $30 \mathrm{~min}$. Data points for a given temperature with the same letter are not significantly different from each other at $\mathrm{P}<0.05$ according to Duncan's Multiple Range Test.

\section{Conclusions and Recommendations}

Two types of sunburn have been distinguished in apples. One type results in a necrotic spot on the sun-exposed side of the fruit, and results from thermal death of cells in the peel when temperatures reach $126 \pm 2^{\circ} \mathrm{F}$. Electrolyte leakage increases significantly in peel from apples with necrosis. The second type is sunburn browning, a sublethal event that results in a yellow, bronze, or brown 
spot on the sun-exposed side of an apple. Sunburn browning occurs when the fruit surface temperatures reach 115 to $120^{\circ} \mathrm{F}$ in the presence of sunlight. The threshold temperature required for sunburn browning appears to be cultivar dependent. Electrolyte leakage from peel that has sunburn browning does not appear to differ from non-sunburned peel.

Readers should be aware that the surface temperature of fruit can be influenced by several factors including solar irradiation, air temperature, relative humidity, wind speed and direction, and tree vigor. It is not uncommon for peel temperature to be at least $18^{\circ} \mathrm{F}$ above ambient temperature, and it can be as much as $29^{\circ} \mathrm{F}$ above ambient temperature on a clear day in the State of Washington when other conditions are favorable. Therefore, sunburn may occur any time air temperature is above $86^{\circ} \mathrm{F}$. The factors that influence fruit surface temperature and their interactions will be the topic of a subsequent paper.

We recommend that growers take measures to prevent the fruit surface temperature from exceeding $113^{\circ} \mathrm{F}$ to prevent sunburn of apple. Evaporative cooling, proper pruning, use of shade cloth, or timely application of particle films such as Surround or RAYNOX are measures that growers can use to protect their fruit from sunburn.

\section{Acknowledgements}

The technical assistance of R. Kammereck is gratefully acknowledged. We also thank the Washington State Tree Fruit Research Commission for financial support.

\section{Literature Cited}

1. Barber, H. N., and Sharpe, P. J. H. 1971. Genetics and physiology of sunscald of fruits. Agric. Meteorol. 8:175-191.

2. Bergh, O., Franken, J., Van Zyl, E. J., Kloppers, F., and Dempers, A. 1980. Sunburn on apples-preliminary results of an investigation conducted during the 1978/ 79 season. The Deciduous Fruit Grower 30:8-22.

3. Brooks, C., and Fisher, D. F. 1926. Some high-temperature effects in apples: Contrasts in the two sides of an apple. J. Agric. Res. 32:1-16.

4. Inaba, M., and Crandall, P. G. 1988. Electrolyte leakage as an indicator of hightemperature injury to harvested mature green tomatoes. J . Amer. Soc. Hort. Sci. 113:96-98.

5. J ones, A. L., and Aldwinckle, H. S., eds. 1990. Compendium of Apple and Pear Diseases. American Phytopathological Society, St. Paul.

6. Rabinowitch, H. D., Ben-David, B., and Friedmann, M. 1986. Light is essential for sunscald induction in cucumber and pepper fruits, whereas heat conditioning provides protection. Scientia Hort. 29:21-29.

7. Rabinowitch, H. D., Kedar, N., and Budowski, P. 1974. Induction of sunscald damage in tomatoes under natural and controlled conditions. Scientia Hort. 2:265-272.

8. Simpson, J., Rom, C. R., and Patterson, M. 1988. Causes and possible controls of sunburn on apples. Good Fruit Grower 39:16-17.

9. Steel, R. G. D., and Torrie, J. H. 1960. Principles and Procedure of Statistics. McGraw-Hill Book Co., Inc., New York.

10. Warner, G. 1997. Sunburn is a hot topic in orchards of Washington. Good Fruit Grower 48:22-23. 